To cite this Article: Lehto, P. \& Rantanen, T. (2017) Robotics in homecare - the development process through a case study, INTED2017 Proceedings, pp. 3444-3452.

DOI: $10.21125 /$ inted.2017.0864

URL: https://library.iated.org/view/LEHTO2017ROB 


\title{
ROBOTICS IN HOMECARE - THE DEVELOPMENT PROCESS THROUGH A CASE STUDY
}

\author{
Paula Lehto, Teemu Rantanen \\ Laurea University of Applied Sciences (FINLAND)
}

\begin{abstract}
In today's Europe nearly every country is facing the huge challenges of an ageing society and population. The digitalisation is spreading rapidly and is reflected in all levels of society, especially the everyday life of citizens [1]. Older people as users or clients and professionals in the field of healthcare and social welfare should be actively involved when robots are developed and tested to be used as new technological solutions. It is currently possible to develop care robots and new digital services that can respond the needs and expectations of older people living independently in their own homes as well as those who receive homecare. The challenge is to develop and study interaction between the robots and users as older people and professionals. The development and piloting of interactive care robots require engaged co-operation from the actors in real life contexts. Cities or municipalities, companies, users, academia, and professionals from public and private health and social care systems should work together to co-create new user-friendly robots and new services.
\end{abstract}

The purpose of this article is to describe a study on how homecare workers see their own work and the current homecare situation. The study is a starting point for conducting a case study and living lab research aiming to answer the question of what new services can be developed through robotics and how care robots can be used in the homecare context. The data was collected through focus group interviews and through an individual-based SWOT assignment. During the first phase of data collection, the main aim was to grasp the meaning of the present situation of homecare. Interviews with homecare workers showed that currently, homecare is demanding, and most older people living at home feel alone and unsafe. Care robots and social robots may be the solution for responding to the needs of older people in homecare. SWOT analyses of robots revealed which types of robots, and how the robots, could be used in homecare. The focus group data is the basis for planning the pilots and tests.

Keywords: care robots, older people, homecare, living lab, robotics.

\section{BACKGOUND}

\subsection{Background of the project}

Europe is tackling today with the huge challenges of ageing society and ageing population. European Union launched the theme Active and Healthy Ageing already the year 2012 and the Program for Active and Healthy Ageing was published as "The European Year for Active Ageing and Solidarity between Generations 2012" [2]. From the point of view elderly people as senior citizens there is a huge need for supporting elderly people's health and wellbeing through the development of the new health and wellbeing technology such as robotics towards new digital services. The digitalization is spreading rapidly reflecting on all levels of the society and especially people's everyday life. The elderly people as users, clients or patients in the field of health care and social welfare should be taken actively along when technological products and new digital services are developed. There is a challenge to develop technology, different types of the robots and digital services that enhance and make possible to be generated a new ecosystem in health care and social welfare context to respond the needs and expectations of the elderly people living independently at their own homes. Cities or municipalities, companies, academic institutions, and professionals from public and private healthcare and social welfare field and e.g. elderly people as users should cooperate together for co creating better and age friendly technology using robots for developing new services.

There is a demand to promote elderly people's health and wellbeing and to support them to cope and live independently at home based on earlier studies elderly people who are living alone are quite often lonely and feel unsafe at home. The challenge is to meet the needs of these elderly people. Also the purpose of the new Act on Care Services for Older People (Act on Supporting the Functional Capacity of the Ageing Population and on Social and Health Care Services for Older People 2013) [3]. In 
Finland is to ensure that elderly people obtain individual care services and caring according to their needs on an equal basis by means of quality social and health care services. Independent living, accessibility and availability of new health services are important in ageing society. In the health care and social welfare sector it is very important to develop e.g. new health services for the elderly people from the point of view citizens not only the point of view organizations

\subsection{Robotics in Health Care}

In health and social welfare field robots can be divided medical robots, institutional robots, personal assistive robots and care robots. (Table 1) Robots can be categorize and named based on different characteristics the robots such as care robots, service robots and social robots [4]. Robots can move and monitor elderly people or they can remind of e.g. medication. Robots enhance also remote online connection or they can offer some games, interaction and discussions. [5] [6].

According to earlier studies there are a lot of positive attitudes towards robots, especially robots related to heavy, dangerous and difficult works and tasks. Based on survey of Eurobarometer (2012) most of informants accept the robot doing everyday hard work but do not see the benefits of the robots in health care or to their own personal wellbeing. Only $18 \%$ approve of robots in healthcare context. [7].

Table 1. Examples of the robots used in health and social care field.

\begin{tabular}{|c|c|c|}
\hline 2 & Target $\left({ }^{*}-\right.$ not yet comeralized $)$ & Examples \\
\hline Medical care & Surgical Robots & $\frac{-170}{2}$ \\
\hline Hospital Logistics & $\begin{array}{l}\text { Hospital Logistics robots } \\
\text { Pharmacy in hospital } \\
\text { Delivery of pharmaceutical }\end{array}$ & \\
\hline Rehabilitation & $\begin{array}{l}\text { Robotic rehab equipment } \\
\text { Robotic prosthetic limbs } \\
\text { External body supports }\end{array}$ & \\
\hline $\begin{array}{l}\text { Personal physical } \\
\text { assistance }\end{array}$ & $\begin{array}{l}\text { Eating ( e.g. robotic spoon) } \\
\text { Moving and exercising } \\
\text { Lifting and carrying things } \\
\text { Cleaning } \\
\text { Cookery* } \\
\text { Dressing* } \\
\text { Hygiene * }\end{array}$ & \\
\hline $\begin{array}{l}\text { Personal cognitive } \\
\text { and social help }\end{array}$ & $\begin{array}{l}\text { Support for selfcare (e.g. motivation for exercising) } \\
\text { Companion } \\
\text { Support for interaction ( Telepresence robots) } \\
\text { Cognitive support (e.g. reminder, finding things }{ }^{\star} \text { ) }\end{array}$ & \\
\hline
\end{tabular}

(Kyrki ym. 2015 [8])

During the last ten years the rise of cognitive robots such as autonomous vehicles and human robots for education and commercial purposes are already available. [9]. The challenge is still to develop interaction between robotics and individuals especially in the field of welfare and social services. Service robots and care robots should be developed and taken in use to respond the huge and rapidly 
increasing demand. There is a need to develop new ICT applications and solutions especially for service robots and care robots.

\subsection{Robots and future of welfare services (ROSE) 2015-2020}

The subproject is a part of the main research project is called Robots and Future of Welfare Services (ROSE) and it is funded by Strategic Research Council, Academy of Finland. The partners in consortium are: Department of Electrical Engineering and Automation, Aalto University Department of Signal Processing, Tampere University of Technology, School of Social Sciences and Humanities, University of Tampere, Business ecosystems, value chains, foresight, VTT Technical Research Centre of Finland, Laurea University of Applied Sciences and School of Business and Management, Lappeenranta University of Technology. The project is coordinated by Aalto University and carries out during the years 2015-2020. [10].

The main project adopts a multidisciplinary and holistic approach to study how advances in robot and perception technologies allow product and service innovation and renewal of welfare services, when such services are developed jointly with users and other stakeholders). In addition, the uptake of the new services requires study of ethical issues and stakeholder participation. All these disciplines are active on the three levels: Individual (human-robot interaction, ethics, and individual support functions), Services (welfare services with robots in different roles) and Society (societal acceptance, renewal of service systems). By joining efforts across disciplines this project aims to go beyond the controversy between technological determinism and social constructivism to help re-define future welfare services. [10].

\section{PURPOSE}

The article is based on main research project called ROSE and especially subproject of Laurea. The purpose is to describe how care robots can be used for supporting elderly people coping at home. The focus also is on how to plan the development process of the service robots or care robots as a case study in the home care context. The aim is to describe a case study finding out how homecare workers see their own work and the present situation at homecare and what needs and expectations homecare workers have in robotics. This study is a starting point for planning and conducting Living Lab research aiming to answer the questions what new services can be developed through the robotics and how care robots can be used in home care context.

The subproject is focusing on the user perspective of robots and robotic innovations in welfare and health services especially in elderly care context. In particular the project aimed to introduce robotics such as service robots and care robots to home care for the elderly people, and the expectations, needs and attitudes of the professionals at homecare.

The research questions are:

1 What is the present situation in homecare described by homecare workers?

2 What kind of clients there are in homecare?

3 How homecare workers assess care robots in homecare?

\section{METHOD}

\subsection{Living lab}

Living lab is a network that integrates an user-centered research and an open innovation [11]. Living lab is an environment that offers future directions of the product development based on users' experiences. A product development can be connected in new products, services, applications through a cocreation process. [11] [12 ]. Leminen and Westerlund [13] defines Living labs as physical regions or virtual environments where public-private-people partnerships, companies, academic institutions and users create, test and validate new products and services in real life situations.

Based on the literature, the Living lab is seen either as a method or as a methodological approach [11]. Living lab can be classified on critical knowledge interests and its goal is to study the phenomena in real life context [14]. The basic principles of Living lab are quite congruent with the action research because both research interest are focusing on practice, actors' involvement and the creation of 
producing new knowledge. Also research interventions are related to the concept of change. The research process is strongly anchored in a real life. [15] [16] [17].

Living lab research is applied in real life situations, rather than in experimental study contexts, since the aim of Living lab research is to solve problems and to find out solutions. Multidisciplinary research groups are often used for the pilots, especially when the focus is on practical orientated questions or problems. [16] [17].

\subsection{Case study}

Case study can be defined as an intensive, qualitative research method in which multiple data collection methods are used. The research focus is on a phenomenon of something what is happening in bounded context. The interest might be on single case, situation, and episode or on multiple cases or events. Often the interest is in processes. [18].

In a user study, the emphasis is on systematic data collection and refining of personal experiences, and the user's participation in the product development process [19]. User data enables information about the characteristics, features, forms and aesthetic qualities of a product or a service. Informants are often an individual or a group of test persons. User data can be collected by studying needs, experiences, ideas and assumptions of designers or testers. Cooperation with users is increasingly common. The idea is to study situations where both the user as a client and the expert or professional is cooperating and piloting together.

User studies are quite often based on qualitative research methods. In addition to methods such as one-to-one interviews, focus groups, observation and participant observation, data can be collected using participative methods such as stories, diaries, thinking aloud, video recordings, visualizations, images and drawings. The data collection such as an observation refers to monitoring the user in his or her own environment. To collect information about the user, his or her activities and user environment, and data about the product in use, need often intensive participation with the user and researcher [19].

In this robotics study the case method and user study will be applied when testing and piloting the use of robots in home care with elderly people. Through a case method it is possible to capture real life happenings and meaning of the robots used. The findings based on the data collected in focus group interviews reflect the evidence for what kind of robots will be chosen and marked out how the robots are applied in real life situations. The Living lab methdodology will be used in this subproject of the main ROSEproject when the chosen robots are tested and piloted in home care context during the next phase of the study. The aim is to choose one or two service robot or care robot which some of eldelry people and homecare workers are able to test and evalaute. The ultimate aim is to get the knowledge for developing new welfare services using service robots or care robots at home or /and homecare context. Living lab approach, user study and user-driven methods integrate various participants in the study such as academia, users and professionals in solving real life problems. For the public health and welfare sector the participation in this subproject of the ROSE RDIproject offers possibilities to gain sociatal innovations and new interventions via robotics in their service actions.

\subsection{Participants}

The participants were home care workers $(n=40)$ from a small municipality in southern part of Finland. Two focus group interviews were organized. There were together 8 small groups, with each group consisting of homecare workers. In the first group 40 homecare workers participated in the interview and 35 participated in latter one. The educational background were nurses, practical nurses, home aids, physiotherapists, social workers or occupational therapists. Three participants were 20-24 years old, seven 25-29 years old, three 30-34 years old, five 35-39 years old, two 40-44 years old and 20 participants were over 45 years old. Participants had working experience in general 17.5 years and in present working place 9.8 years.

\subsection{Data collection}

The data was collected through focus group interviews [20]. The interviews were conducted in two phases and through written individual assignment including strengths, weaknesses, opportunities and threats (SWOT) of the robots in homecare. During the first phase of data collection the main aim was to grasp the meaning of the present situation of homecare described by home care workers. The 
second phase focused on homecare workers' assessments of how robots can be used to support elderly people at home.in homecare context.

\subsection{Data analysis}

The data was analysed using qualitative content analysis. [21] [22]. First all interviews were transcribed word by word. The data was read briefly as a whole in order to get the picture of the content. After that the data was reduced, coded and categorized using inductive qualitative content analysis. The data was mapped and formulated first as subcategories, then as categories and then as main categories. The following example shows the formulated main category which was grounded from the data.

Table 2. One example of qualitative analysis.

\begin{tabular}{|l|l|l|l|}
\hline reduction & subcategory & category & main category \\
if there is a camera at home there is no privacy & camera at home & fear of & fears to robotics \\
privacy is decreasing & privacy & decreased & \\
integrity can be decreased & integrity & integrity & \\
\hline
\end{tabular}

The purpose of the second phase of the data collection was to find out how home care workers assess how robots can be used in homecare. Based on the qualitative analysis the individual assignment including strengths, weaknesses, opportunities and threats were mapped and clustered. The findings were collected and categorized using SWOT table.

\section{FINDINGS}

\subsection{Descriptions of the present situation at homecare}

Homecare workers' descriptions of the present situation in homecare were grounded from the interview data and the main categories are: client in homecare, circumstances in homecare environments, episodes of homecare visit and used time and challenges of homecare.

Clients in homecare were described based on health status and holistic wellbeing, loneliness and unsafety, lack of mobility and meaning of the role of significant other. Clients in homecare are nowadays more and more in bad condition and ill. They have several illnesses and problems. There are more than before those elderly people with memory problems and dementia. Homecare worker meet often client at home in sudden attack of disease or that he or she has fallen at home. Loneliness and unsafety were mentioned often. Quite many of the clients are living alone are distressed and have fears to cope at home. They need more and more help and support. Spouses of the clients are often also unwell and have problems to cope at home. Both of elderly people in the family need often help at home. Other family members have a lot of worries about how the parents are coping.

Circumstances at home environment as a main category grounded on challenges at home, challenges in activity of daily living and variety of conditions and spaces at home. The house of the elderly might be located quite far of way from the neighbors and services. Weather conditions especially in wintertime are quite hard for elderly to cope independently at home. Also there are some houses lacking the basic facilities such as inside water or bath.

Contents of the homecare work, episodes in home visits and allocation of time are challenging and demanding. There are multiple tasks and actions to be handled in homecare e.g. when the client is hospitalized or after admission. Consultations, assessments and sudden situations require more and more homecare workers' time and resources. Documentations and management take a lot of time and this all is away from the true presence with the client at home and discussions with her or him.

"if you think, that one old person is sitting alone and eats, it is much more better if the nurse could sit beside him or her and in that case also food tastes better and the situation is social" 
Challenges in homecare during the shift are related to clients' health changes, transitions from home to hospital or vice versa, requests and consultations, changes during the shift and to office work. Clients' health changes need rapid actions and interventions at home or transition to the hospital. Additional or extra home visits concern often safety alarms or checkups. If the colleague is sick and there are planned home visits, there will be direct changes during the shifts. The main worry for the homecare workers is the thought how the client copes alone at home. The challenge for the homecare workers is to complete all tasks and duties before the shift ends. There are a lot of documentations and ICT based work in the office. The challenge is to utilize more ICT, communications and to update professional competence.

"Well if there is sudden attack and or client has fallen down and you must wait for another person to help or lift or sometimes you must ask help from service house if they have time to come and it will take time."

\subsection{Findings of SWOT analysis based on homecare workers' descriptions}

Homecare workers reflected their own thinking how to use robots in their own work, what are the strengths, weaknesses, opportunities and threats if and when robots are used in homecare. They filled the SWOT analysis as individual assignment. As a summary of the SWOT analysis, the findings are grouped and presented from the perspective of client and of the perspective of workers including the technological perspective. (Table 3)

Table 3. Summary of the SWOT.

\begin{tabular}{|l|l|}
\hline Strengths (care robots) & Weaknesses (care robots) \\
\hline Client's perspective & Client's perspective \\
Reducing loneliness (music, movies) & Attitudes, fears \\
Accompany, keeping connected & Elderly people's limited learning capability \\
Rehabilitation, gym & Physical circumstances at homes vary \\
Brings some variation in daily life & Movements of the robots e.g. in old houses and \\
Eases activity of daily living (cleaning, shopping) & houses with more than one floor \\
Physical assistance, gives a thing from the floor & Pets at home environment \\
Improving safety monitoring & \\
Home care workers' perspective & \\
Releases more time for other work & Home care workers' perspective \\
Eases the work in homecare (e.g. the care robot \\
should dress support hoses (socks) to the client \\
$\begin{array}{l}\text { Monitoring clients' (wellbeing, measurements } \\
\text { (blood pressure, heart rate) }\end{array}$ & Technology \\
Care robot alarms (falling down, low or high & Reliability (e.g. duration of battery) \\
measurements) & Technical difficulties and disturbances, Internet \\
Telepresence, online connection, calming the client & connection \\
Guidance, integration of voice and picture & Features of the robot dirt, water resistance \\
Reminders (medication, eating, drinking) & Limited functions \\
\hline
\end{tabular}




\begin{tabular}{|l|l|}
\hline Opportunities (care robots) & Threats (care robots) \\
\hline Client's perspective & Client's perspective \\
Willingness to experiment & Fears, attitudes, resistance \\
Elderly people who want voluntary to test and are & Limitations with e.g. elderly people with memory \\
interested in using robots & problems \\
Homecare workers' perspective & Housing circumstances might not support the use \\
Increasing awareness, prior experiences, & of robots \\
evidence-based knowledge & Environmental challenges (bad weather conditions, \\
Improving know-how & Homecare workers perspective \\
Positive attitude will be spread & Workers' negative attitudes towards robots \\
Worker's openness, interested in testing & Lack of imagination (how to use robots in work) \\
Utilization of media and marketing & \\
Designing versatile services & \\
Service availability & \\
Accessible pricing & \\
\hline
\end{tabular}

Findings produced a new knowledge about the present situation and robots in home care context. Findings will be the basis for the design of Livinglab pilots in the project. Through the user-driven methods such as pictures or stories [19] during the cocreation process, homecare workers will be committed in the development process to use the possible technology such as care robots in the home care context and how new services can be ideated.

\section{DISCUSSION}

\subsection{Ethical issues}

Permission for the research of the Laurea project was granted by the participative municipality. The research was conducted accordance with good research practice and guidelines from Laurea University of Applied Sciences and the Ethics Committee of Federation of Universities of Applied Sciences (FUAS). Permission was granted also by the participative municipality. The ethical research guidelines and practices were strictly complied with during the project. [23] [24] [25].

The research participants were elderly homecare workers and they participated in two different phases of the study. The ethical aspects of the study were carefully checked and the participants' rights were protected. Research participants were asked to write informed consent. The background and the purpose of the study were explained before the participants signed the informed consent. Also the rights of the participants were told. The special attention were paid to ethical and legal rights and confidentiality. The participants were told that it is possible for them to drop out the study whenever they feel so. Also the knowledge that this study and participation in it, did not affect the homecare workers position in the work. The research data was carefully stored during the research process and it will be destroyed at the end of the research project. The research findings will be documented and reported with care.

\subsection{Trustworthiness}

Trustworthiness has been analyzed during the research process from the perspective of data collection and data analysis. In the study, the reliability were ensured on different phases of the data collection, and the findings were based on the data. The data was collected using focus group interviews and SWOT. The qualitative content analysis of the data were used. Transferability of the findings were essential throughout the research project. The data analysis was based on the recorded and transcribed documents. The authentic quotes were used when reporting the findings. [20] [23]. The quotes demonstrate the consistency of the data analysis. 


\subsection{Future challenges}

For the further phase of the study the challenge is how elderly people as clients or users and homecare workers will be in an active role in testingand pilotind care robots in real life situations. Also the challenge is to design and cocreate together possible new services using robots in homecare context. Living lab approach and methodology will be used when testing robots with and for eldlery people living at their own homes or in service care settings. The voice of the participants is crucial in empowering the eldelry people in their own life and in empowering professionals in developeing their own work. In the conference the videodemonstration of the robots and the first research findings as an evidence on choosing the robots for tests will be presentead in virtual session.

\section{REFERENCES}

[1] Digital Agenda in Europe 2012. http://ec.europa.eu/digital-agenda/en/digital-agenda-europe. Read 28.12.2016.

[2] Active and Healthy Ageing 2012. http://ec.europa.eu/health/ageing/policy/index-en.htm. Read 4.1.2016.

[3] Act on Supporting the Functional Capacity of the Ageing Population and Social and Health Care Services. https://www.finlex.fi/en/laki/kaannokset/2012/en20120980. (read 28.1.2016)

[4] Kangasniemi M., Pietilä A-M. \& Häggman-Laitila A. (2016) Automatiikka ja robotiikka hoitotyöntekijöiden työn muutoksessa. Tutkiva Hoitotyö 14(2),40-45.

[5] Vermeersch P, Sampsel D.D \& Kleman C. 2015. Acceptability and usability of a telepresence robot for geriatric primary care: A pilot. Geriatric Nursing, 234-238.

[6] Kristoffersson A, Coradeschi S, Loutfi A \& Severinsson-Eklundh K. 2011. An exploratory study of health professionals' attitudes about robotic telepresence technology. Journal of Technology in Human Services 29, 263-283.

[7] EuroBarometer 2013. http://ec.europa.eu/public_opinion/archives/ebs/ebs_382_en.pdf. Read 4.1.2017.

[8] Kyrki, K., Coco, K., Hennala, L., Laitinen, A., Lehto, P., Melkas, H., Niemelä, M. \& Pekkarinen, S. 2016. Robotit ja hyvinvointipalvelujen tulevaisuus (ROSE-konsortio). Tilannekuvaraportti 2015. Strateginen tutkimus. Suomen Akatemia. http://www.aka.fi/globalassets/33stn/tilannekuvaraportit/tech-kyrki-robotiikkahyvinvointijaterveyspalveluissa_20160104.pdf (read 28.12.2016).

[9] Mataric' M, Okamura A, Christensen H. A (2015) Research Roadmap for Medical and Healthcare Robotics. In: A Roadmap for US Robotics. From Internet to Robotics; http://www.usrobotics.us/reports/CCC\%20Report.pdf; retrieved 28 July, 2015.

[10] ROSE www.roseproject.aalto.fi https://twitter.com/ROSERobotic

[11] Leminen, S. (2015). LivingLabs as open innovation networks.Aalto University publication series. Doctoral Dissertations 132/2015. Unigrafia Oy, Helsinki. https://aaltodoc.aalto.fi. (luettu 5.10.2016).

[12] Leminen, S., Westerlund, M. \& Nyström, A. (2012). Living Labs as Open -Innovation Networks. Technology Innovation Management Review. 1-6. http://timreview.ca/article/602 Read 5.1.2016

[13] Leminen, S. \& Westerlund, M. (2011). Managing the challenges of becoming an open innovation company; experiences from living Labs. Technology Innovation. 19-25. Management Review http://timreview.ca/article/489 Read 5.1.2016

[14] Kyrö, P. (2004). Benchmarking as an Action Research Process. Benchmarking. An International Journal. 11(1),52-73.

[15] Moore, J., Crozier, K. \& Kite, K. (2012). An Action research approach for developing research and innovation in nursing and midwifery practice: Building research capacity in one NHS foundation trust. Nurse Education Today (32):39-45.

[16] Lehto, P. (2011). Action Research and Userdriven methods in the Safe Home Project. In Lehto, P. \& Leskelä, J. (eds.) Interactive CaringTV® and Userdriven eServices. pp. 18-38. The Safe Home Project: Final Report Laurea UAS Publications B45. Edita Prima Oy, Helsinki. 
(http://www.laurea.fi/fi/tutkimus_ja_kehitys/julkaisut/julkaisuarkisto/Documents/B45.PDF).

[17] Reason, P. \& Bradbury, H. (ds. (2008). The Sage Handbook of Action Research: Participative Inquiry and Practice. 2nd edition. Sage Publications Ltd. London.

[18] Yin, R.K. (1994) Case Study Research, Design and Methods. Newton Park: Sage.

[19] Hyysalo, S. 2009. Käyttäjä tuotekehityksessä - Tieto, tutkimus, menetelmät. (User in product development - Knowledge, Research, Methods). University of Art and Design publications B 97. Helsinki.

[20] Stewart D.W. \& Shamdasani P.N. (2015) Focus groups: Theory and practice. $3^{\text {rd }}$ ed. Sage, Thousand Oaks Ca.

[21] Holloway I. \& Wheeler S. (2010) Qualitative reserach in nursing and health care. Blackwell, Oxford.

[22] Silverman, D. (2001). Doing qualitative research. A practical handbook. Sage Publications Ltd, London.

[23] Ethical principles of research in the humanities and social and behavioural sciences and proposals for ethical review (2009). http://www.tenk.fi/sites/tenk.fi/files/ethicalprinciples.pdf (read 28.12.2016).

[24] Pietarinen, J. 2002. Eettiset perusvaatimukset tutkimustyössä. Teoksessa Karjalainen, S., Launis, V., Pelkonen, R. \& Pietarinen, J. (Toim.) Tutkijan eettiset valinnat. Tampere. TammerPaino. 58-69.

[25] Topo, P. 2007. Dementia, teknologia ja etiikka. Gerontologia. The Finnish Society for Growth and Ageing Research publications 3/2007, 221-230. 